\title{
Assessment of Bronchial Obstruction Using Lateral Pressure Measurement during Bronchoscopy
}

\author{
Hiroki Nishine Takehiko Hiramoto Takeo Inoue Naoki Furuya Hirotaka Kida \\ Hiroshi Handa Seiichi Nobuyama Masamichi Mineshita Teruomi Miyazawa
}

Division of Respiratory Medicine, Department of Internal Medicine, St. Marianna University School of Medicine, Kawasaki, Japan

\section{Keywords}

Airway stenosis - Dyspnea · Flow limitation - Phase shift ·

Pressure-pressure curve $\cdot$ Site of maximal obstruction

\begin{abstract}
Background: In patients with bronchial obstruction estimating the location of the maximal obstruction is crucial for guiding interventional bronchoscopy. However, flow-volume curves cannot discriminate between the right and left lungs. Objectives: The aim of this study was to physiologically evaluate bronchial obstruction during interventional bronchoscopy. Methods: We prospectively measured lateral airway pressure $\left(\mathrm{P}_{\text {lat }}\right)$ at either side of the obstruction using a double-lumen catheter (pressure-pressure [P-P] curve) simultaneously to assess the degree of bronchial obstruction in 22 patients. The shape of the P-P curve was assessed to confirm the site of maximal obstruction. Results: In the experimental study, $\mathrm{P}_{\text {lat }}$ was uniform between both bronchi in the normal model. For the unilateral and bilateral obstruction models, a phase shift was only seen for the more obstructed side. In healthy subjects, the angle of the P-P curve was close to $45^{\circ}$ and linear in shape. In patients with bronchial obstruction, the angle was much smaller but approached $45^{\circ}$ after the bronchoscopic procedure. The degree of bronchial obstruction was significantly correlated
\end{abstract}

๑ 2017 S. Karger AG, Basel with the angle of the P-P curve $(r=-0.51, p<0.01)$. Dyspnea significantly increased when the airway lumen was obstructed by more than $60 \%(p<0.0001)$, and when the P-P curve appeared loop-shaped $(p<0.01)$. Conclusions: The shape of the P-P curve could be used to detect the site of maximal obstruction for the optimal positioning of the stent and assess the need for additional procedures in real time in patients with bronchial obstruction.

(c) 2017 S. Karger AG, Basel

\section{Introduction}

In patients with severe malignant airway stenosis, interventional bronchoscopy is considered as a method of maintaining airway patency [1]. The positioning of the stent at the flow-limiting segment provides the greatest functional benefit to patients with central airway stenosis [2-5]. Thus, estimating the location of the flow-limiting segment and airway mechanics is crucial in guiding interventional bronchoscopy. To date, however, there is no quantitative examination to assess a bronchial obstruction during interventional bronchoscopy. Therefore, we proposed a simple method of lateral airway pressure $\left(\mathrm{P}_{\text {lat }}\right)$ measurement during bronchoscopy. In our previous study, pressure differences were used to locate the site of

\section{KARGER}

E-Mail karger@karger.com

www.karger.com/res
Teruomi Miyazawa

St. Marianna University School of Medicine

2-16-1 Sugao Miyamae-ku

Kawasaki 216-8511 (Japan)

E-Mail miyazawat@marianna-u.ac.jp 
maximal obstruction for the optimal positioning of the stent [6]. The angle of the pressure-pressure (P-P) curve could quantitatively assess the degree of tracheal obstruction, and the shape of the P-P curve was useful in analyzing the nature of the stenosis. Since stenting has become a valuable therapeutic strategy for patients with tracheobronchial obstruction, an assessment modality for patients with bronchial obstruction is also important.

In regard to physiological assessments, we noticed distinct flow-volume curve patterns specific to the type of obstruction [5]. Although flow-volume curves are widely used in daily clinical settings, they cannot discriminate between the left and right lungs. Furthermore, in patients with bronchial obstruction, pulmonary function tests may not change significantly after intervention [7]. It can be challenging to estimate the relationship among pulmonary function, dyspnea, and the site of bronchial obstruction by bronchoscopy alone. We therefore utilized $\mathrm{P}_{\text {lat }}$ measurements to estimate the outcome of intervention in patients with bronchial obstruction.

The aim of this study is to assess the efficacy and feasibility of $\mathrm{P}_{\text {lat }}$ measurement to determine the effects of graded main stem bronchial obstruction. To validate this method, we created an experimental model to simulate bronchial obstruction (online suppl. Fig. 1; for all online suppl. material, see www.karger.com/doi/10.1159/000481572). To assess the usefulness in a clinical setting, we assessed the site of maximal obstruction by measuring $\mathrm{P}_{\text {lat }}$.

Some of these results have been previously reported in the form of abstracts [8].

\section{Materials and Methods}

\section{Experimental Model Validation}

A silicone $Y$ tube was set in an airtight rigid chamber. The diameters of the $\mathrm{Y}$ tube were $14 \mathrm{~mm}$ at the tracheal segment and 12 $\mathrm{mm}$ for both bronchial segments. By inserting a silicone balloon into the lumen at the bronchial segments and inflating with a plastic syringe, we constructed a practical model of bronchial obstruction (online suppl. Fig. 1). Pressure in the chamber was exposed to positive and negative driving pressure by inflating and deflating $500 \mathrm{~mL}$ regularly to emulate a regular respiratory cycle $(15 / \mathrm{min})$.

$\mathrm{P}_{\text {lat }}$ was measured with a double lumen airway catheter (Fuji Systems, Tokyo, Japan) [6] simultaneously at two points: the bifurcated (carina) and peripheral segments (bronchi). The catheter is constructed of nylon elastomer with 2 holes manufactured into the side at $5-\mathrm{cm}$ intervals, with an outer diameter of $1.7 \mathrm{~mm}$. The catheter was connected to a container with two identical pressure transducers (SCX01DN; Sensortechnics, Munich, Germany). Flow was measured with a pneumotachograph (Lilly type; Chest Corp., Tokyo, Japan) and a differential pressure transducer (SCXL004DN; Sensortechnics, Munich, Germany). Pressures at the 2 points were plotted ( $\mathrm{x}$-axis as pressure at the distal site; $\mathrm{y}$-axis as pressure at the

Lateral Pressure Measurement at the Bronchus proximal site), and the angle of the P-P curve was measured. The angle of the P-P curve was defined as the angle between the peak inspiratory and expiratory pressure points and the baseline of the angle. $\mathrm{P}_{\text {lat }}$ and flow were continuously recorded digitally into a personal computer, and data analysis was completed using PowerLab (PowerLab8/30; ADInstruments, Bella Vista, Australia).

\section{Clinical Feasibility}

Between August 2007 and August 2013, interventional bronchoscopy was prospectively performed on 180 patients. The Research Ethics Committee at St. Marianna University School of Medicine approved this study (No1289). Of the 180 patients, 80 underwent $\mathrm{P}_{\text {lat }}$ measurements as an adjunct to bronchoscopy. Twenty-two patients with bronchial obstruction underwent $\mathrm{P}_{\text {lat }}$ measurement after meeting the following criteria: patients with grade 2 dyspnea or higher on the Modified Medical Research Council (MMRC) scale, and a minimum of $50 \%$ obstruction on multidetector computed tomography. We also compared 15 healthy subjects.

Multidetector computed tomography was performed by 64 -detector row CT scanner (Aquilion-64; Toshiba Medical, Tokyo, Japan) as previously described $[9,10]$. The degree of bronchial obstruction was defined as (CSA normal - CSA actual)/CSA normal (CSA, cross-sectional area).

All patients were anesthetized by an intravenous injection of propofol. After intubation with a rigid bronchoscope (EFER, La Ciotat, France), a flexible bronchoscope (Olympus P260F; Olympus, Tokyo, Japan) was placed in a target bronchus, and a double lumen airway catheter was inserted through the working channel of the bronchoscope (online suppl. Fig. 2). $\mathrm{P}_{\text {lat }}$ was measured simultaneously at two points (proximal and distal sites of the obstruction) during spontaneous breathing. After measurements were recorded, we described the P-P curve, and analyzed the pressure difference and the angle of the P-P curve.

\section{Statistical Analysis}

The primary end point was to assess the shape of the P-P curve to assess the site of maximum bronchial obstruction. All analyses were performed using SPSS software (ver19; IBM, Armonk, NY, USA). Continuous variables before and after intervention were tested by Wilcoxon signed-rank test. The correlation among pressure difference, the angle of the P-P curve, and the CSA were evaluated using Spearman's correlation coefficient. All results are presented as mean $\pm \mathrm{SD}$, and $p$ values $<0.05$ were considered statistically significant. Responders were defined as any patient with an increase in forced vital capacity or forced expiratory volume in $1 \mathrm{~s}$ $\left(\mathrm{FEV}_{1}\right)$ exceeding $200 \mathrm{~mL}$ and $12 \%$ of the baseline value by pulmonary function test. Patients with improvements on the MMRC scale of 2 or more were considered to be clinical responders.

\section{Results}

\section{Experimental Model Validation}

For the normal bronchial model, $\mathrm{P}_{\text {lat }}$ was uniform between the black and dotted lines (Fig. 1a, c). The angle of the P-P curve reached $45^{\circ}$ for each side indicating no obstructions were present $\left(45^{\circ}\right.$ right and $43.9^{\circ}$ left side) (Fig. 1b, d). 


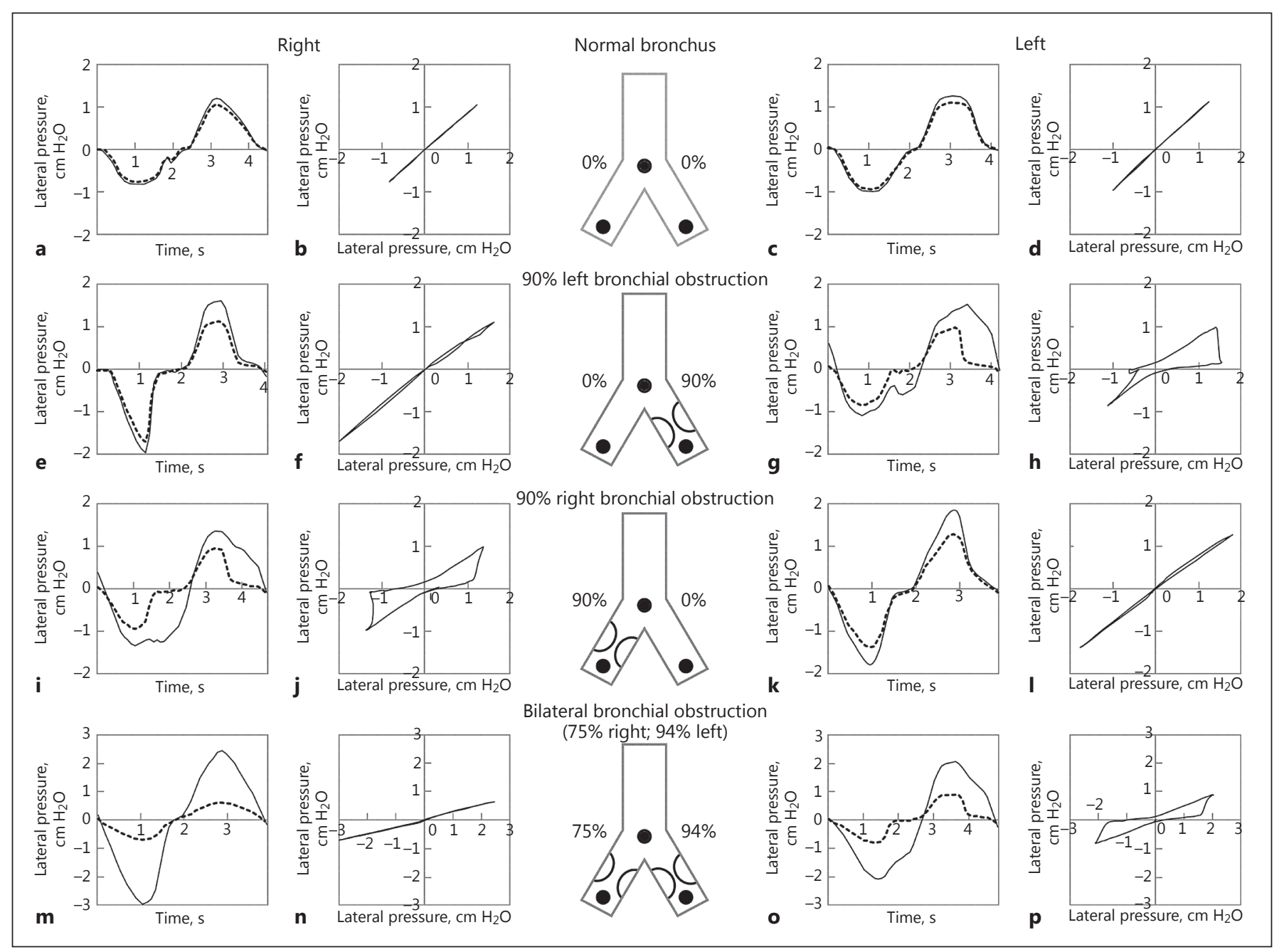

Fig. 1. Experimental models for bronchial obstruction. a-d Normal bronchus. e-h Left bronchial obstruction (90\% obstruction). i-I Right bronchial obstruction ( $90 \%$ obstruction). $\mathbf{m}-\mathbf{p}$ Bilateral bronchial obstruction (right $75 \%$ obstruction; left $94 \%$ obstruction). The black lines show the peripheral segment (bronchus) while the dotted lines indicate the bifurcated segment (carina) for all models.

For the left bronchial obstruction model, a pressure difference was seen for the left side only (Fig. 1e, g). Phase shifts between the distal and proximal sides of the obstruction were seen during each breathing cycle for the left side (Fig. 1g) and the P-P curve appeared loop-shaped (Fig. 1h). For the right side, the shape of the P-P curve was linear (Fig. 1f).

For the right bronchial obstruction model, a pressure difference was seen for the right side only (Fig. 1i, k). Phase shift occurred for the right side (Fig. 1i) and the P-P curve appeared loop-shaped (Fig. 1j). For the left side, the shape of the P-P curve was linear (Fig. 11).

For the bilateral bronchial obstruction model, pressure differences were seen for the left and right sides
(Fig. $1 \mathrm{~m}, \mathrm{o}$ ), but phase shift only occurred at the more obstructed side (left side) (Fig. 1o). For the less obstructed side (right side), the angle of the P-P curve was smaller, but the shape of the P-P curve was linear (Fig. 1n). On the other hand, the more obstructed side (left side) became loop-shaped (Fig. 1p).

Correlation between the pressure difference and the angle of P-P curves for the degree of bronchial obstruction is shown in Figure 2. The degree of bronchial obstruction was significantly correlated with the pressure difference $(r=0.96, p<0.01)$ (Fig. 2a) and the angle of the P-P curve $(r=-0.95, p<0.01)$ (Fig. 2b). 


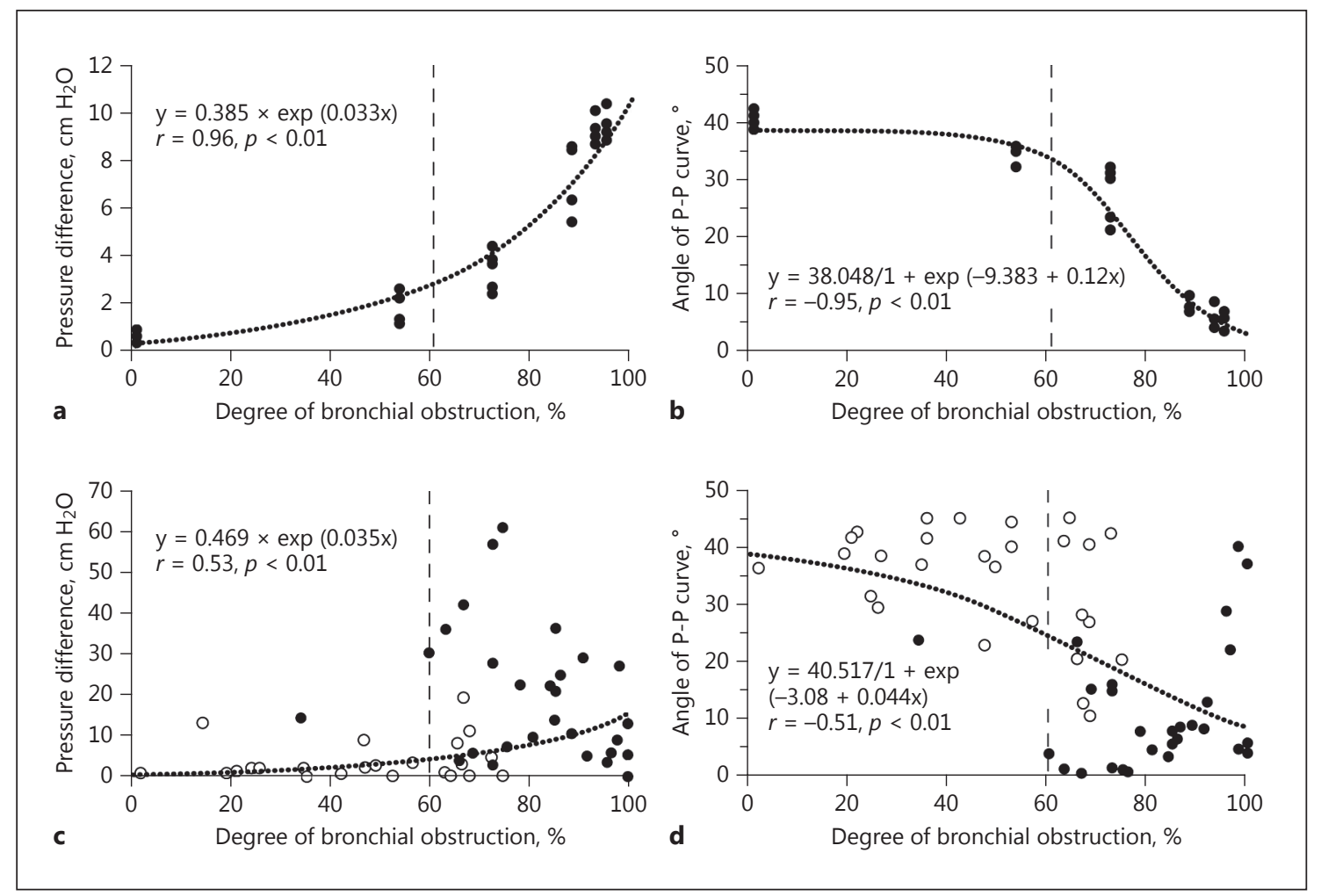

Fig. 2. The correlations between the angle of $\mathrm{P}-\mathrm{P}$ curves and the degree of bronchial obstruction. $\mathbf{a}, \mathbf{b}$ Experimental model. c, d Clinical data. The dotted lines indicate a threshold of $60 \%$ bronchial obstruction. The pressure difference (a) and the angle of P-P curves (b) are significantly correlated with the degree of bronchial obstruction. a The pressure difference increased significantly from $60 \%$ obstruction. c, $\mathbf{d}$ The black circles show before intervention and the white circles indicate after intervention. The pressure difference and the angle of the pressurepressure (P-P) curves are significantly correlated with the degree of bronchial obstruction.

\section{Clinical Feasibility}

$\mathrm{P}_{\text {lat }}$ measurements were recorded in 15 healthy subjects and 22 patients with bronchial obstruction (Table 1 ). $\mathrm{P}_{\text {lat }}$ measurements required an additional 5 min of procedure time, and no adverse events were noted as a result of this bronchoscopic approach.

In healthy subjects, there were no flow limitations or pressure differences seen between the lower bronchus and carina $\left(0.28 \pm 0.39 \mathrm{~cm} \mathrm{H}_{2} \mathrm{O}\right)$ during tidal breathing. The P-P curves were linear, and the angle of the P-P curves was close to $45^{\circ}\left(44.3 \pm 1.3^{\circ}\right)$.

In the 5 patients with bilateral bronchial obstruction, bilateral wheezing was present. In the 5 patients with moderate unilateral bronchial obstruction (mean $81 \pm$ $12 \%$ ), unilateral wheezing was present (Table 1). In the 8 patients with severe unilateral bronchial obstruction (mean $91 \pm 9 \%$ ) and 2 patients with atelectasis, a decrease of breath sounds or a total absence of breath sounds was noted (Table 1). In the 2 patients with mild unilateral bronchial obstruction (below 70\% obstruction), normal breath sounds were present (Table 1).

Characteristics for patients with bronchial obstruction are shown in Table 2. Seventeen patients were diagnosed with unilateral and 5 with bilateral bronchial obstruction. In 22 patients, clinical assessment and bronchoscopic examination and in 19 patients, pulmonary function tests were performed before and after interventional bronchoscopy. Pulmonary function tests were not performed in 3 patients with poor performance status.

$\mathrm{FEV}_{1}$ and peak expiratory flow increased significantly after procedures ( $p<0.01$ and $p<0.01$, respectively), and an improvement was seen on the MMRC scale $(p<0.01)$ (Table 3). Significant improvements in all patients were observed in the degree of bronchial obstruction $(p<0.01)$, pressure difference $(p<0.01)$, and for the angle of the P-P curves $(p<0.01)$ (Table 3$)$. The proportion of responders 
Table 1. Demographics and the pulmonary baseline in patients with bronchial obstruction

\begin{tabular}{lcc}
\hline & $\begin{array}{c}\text { Healthy subjects } \\
(n=15)\end{array}$ & $\begin{array}{l}\text { Bronchial } \\
\text { obstruction patients } \\
(n=22)\end{array}$ \\
& & \\
\hline Age, years & & $56.4 \pm 10.7$ \\
$\quad$ Mean \pm SD & $63.3 \pm 13.4$ & $28-73$ \\
$\quad$ Range & $26-84$ & \\
\hline Sex, $n$ & & 13 \\
$\quad$ Male & 10 & 9 \\
$\quad$ Female & 5 & $162.5 \pm 10.0$ \\
\hline Height, cm & $159.3 \pm 10.0$ & $57.7 \pm 13.3$ \\
Body weight, kg & $54.1 \pm 10.5$ & $2.5 \pm 0.9$ \\
VC, L & $3.1 \pm 0.8$ & $74.9 \pm 19.7$ \\
VC, \% predicted & $103.3 \pm 13.6$ & $2.5 \pm 0.9$ \\
FVC, L & $3.1 \pm 0.8$ & $1.4 \pm 0.6$ \\
FEV, L & $2.4 \pm 0.6$ & $55.4 \pm 20.7$ \\
FEV ${ }_{1}$, \% predicted & $101.5 \pm 14.4$ & $60.5 \pm 19.0$ \\
FEV $/$ FVC, \% & $75.7 \pm 8.9$ & $3.4 \pm 1.7$ \\
PEF, L/s & $7.3 \pm 1.9$ & \\
\hline Auscultation, $n$ & & 5 \\
Unilateral wheezing & & 5 \\
Bilateral wheezing & & 2 \\
Decreased breath sounds & \\
Total absence of breath sounds & \\
Normal breath sounds & & \\
\hline
\end{tabular}

Comparisons between healthy subjects and patients were made using unpaired $t$ tests for quantitative variables and Fisher's exact tests for categorical variables. Values are represented as mean \pm standard deviation. VC, vital capacity; FVC, forced vital capacity; $\mathrm{FEV}_{1}$, forced expiratory volume in $1 \mathrm{~s} ; \mathrm{PEF}$, peak expiratory flow.

to treatment was $72.7 \%$ for the MMRC scale, $47.4 \%$ for forced vital capacity, and $68.4 \%$ for $\mathrm{FEV}_{1}$ (Table 3).

Correlations between the pressure difference and the degree of bronchial obstruction and between the angle of the P-P curve and the degree of bronchial obstruction are shown in Figure 2c, d. The degree of bronchial obstruction was significantly correlated with the pressure difference $(r=0.53, p<0.01)$ and the angle of the P-P curve $(r=-0.51, p<0.01)$. Pressure differences increased significantly from the $60 \%$ obstruction $(p<0.001)$ (Fig. $2 c)$. If the bronchial obstruction was severe, the angle of the $\mathrm{P}-\mathrm{P}$ curve was close to $0^{\circ}$. However, after interventional bronchoscopy, the degree of bronchial obstruction decreased and the angle of the P-P curve was close to $45^{\circ}$ (Fig. 2d). Receiver-operating characteristic analysis indicated that the optimal cutoff point for the pressure difference and the angle of the P-P curves was $60 \%$ for bron- chial obstruction, with 65.5 and $72 \%$ sensitivity and 58.6 and $72 \%$ specificity, respectively. The optimal cutoff point for the angle of the P-P curve was $24.6^{\circ}$ to detect a bronchial obstruction of more than $60 \%$.

Dyspnea significantly increased when the airway lumen was obstructed by more than $60 \%(p<0.0001)$. The mean degrees of bronchial obstruction for each MMRC grade were as follows: $50.4 \%$ for grade $0,57.1 \%$ for grade $1,68.7 \%$ for grade $2,89.7 \%$ for grade 3 , and $88.7 \%$ for grade 4 ( $p$ for trend $<0.001$ ). Dyspnea significantly increased when the P-P curve appeared loop-shaped compared to when the P-P curve appeared linear $(p<$ $0.01)$.

In patients with unilateral bronchial obstruction, a significant pressure difference was seen for the obstructed side and the P-P curve appeared loop-shaped. However, for the unaffected side there was no pressure difference seen and the P-P curve was linear. After interventional bronchoscopy, the CSA increased and the pressure difference disappeared. The P-P curve was close to $45^{\circ}$ and appeared linear.

$\mathrm{P}_{\text {lat }}$ measurement identified the need for additional treatments in 4 patients with bilateral main stem bronchial obstruction during interventional bronchoscopy. A typical bilateral obstruction case is shown in Figure 3. Figure 3 shows a patient with a bilateral obstruction at both main stem bronchi due to adenocarcinoma. 3D-CT visualized an intraluminal tumor extending from the carina to both main stem bronchi (Fig. 3c). The left main stem bronchus was more obstructed than the right (89\% left vs. $81 \%$ right), and there were considerable pressure differences noted between the carina and both lower bronchi during inspiration and expiration (Fig. 3a, d). The angle of the P-P curves for both main stem bronchi decreased. For the less obstructed bronchus (right), the shape of P-P curve was linear (Fig. $3 b$ ). On the other hand, the more obstructed bronchus (left) was loopshaped (Fig. 3e).

An initial stent was placed from the lower trachea to the left main stem bronchus (Fig. 3h), resulting in a decrease in the pressure difference. However, a large pressure difference remained for the right main stem bronchus (Fig. 3f, i). After initial stenting, the angle of the P-P curve increased from 9 to $21.8^{\circ}$ for the left main stem bronchus (Fig. 3j). The shape of the P-P curve became close to linear for the left side but remained loop-shaped for the right side (Fig. 3g, j).

During the same procedure, the site of maximal obstruction was then confirmed at the right main stem bronchus requiring additional stenting. Subsequently, a 
Table 2. Diagnosis, classification, and the number of bronchial obstruction cases

\begin{tabular}{|c|c|c|c|c|c|c|c|c|}
\hline \multirow[t]{3}{*}{ Diagnosis } & \multicolumn{4}{|c|}{ Site of obstruction } & \multicolumn{4}{|c|}{ Type of obstruction } \\
\hline & \multicolumn{2}{|l|}{ unilateral } & \multicolumn{2}{|l|}{ bilateral } & \multicolumn{2}{|l|}{ malignant } & \multicolumn{2}{|l|}{ benign } \\
\hline & $\begin{array}{l}\text { right main } \\
\text { bronchus }\end{array}$ & $\begin{array}{l}\text { bronchus } \\
\text { intermedius }\end{array}$ & $\begin{array}{l}\text { left main } \\
\text { bronchus }\end{array}$ & $\begin{array}{l}\text { right/left } \\
\text { bronchi }\end{array}$ & endoluminal & mixed & $\begin{array}{l}\text { granula- } \\
\text { tion }\end{array}$ & $\begin{array}{l}\text { mala- } \\
\text { cia }\end{array}$ \\
\hline Lung cancer & 8 & 1 & 3 & 2 & & 14 & & \\
\hline Esophageal cancer & & & 1 & & & 1 & & \\
\hline Adenoid cystic carcinoma & & & 1 & & 1 & & & \\
\hline Malignant lymphoma & 1 & & & & & 1 & & \\
\hline Leiomyoma & & & 1 & & 1 & & & \\
\hline Bronchial tuberculosis & & & 2 & & & & 1 & 1 \\
\hline Relapsing polychondritis & & & & 2 & & & & 2 \\
\hline Total & 9 & 1 & 7 & 5 & 1 & 17 & 1 & 3 \\
\hline
\end{tabular}

Table 3. Dyspnea score, pulmonary function tests, the degree of obstruction, pressure difference, and angle of the $\mathrm{P}-\mathrm{P}$ curves in patients with bronchial obstruction before and after interventional bronchoscopy

\begin{tabular}{lccc}
\hline & Before & After & Responders \\
\hline MMRC scale & $2.7 \pm 1.1$ & $0.7 \pm 0.7^{* *}$ & $16 / 22(72.7 \%)$ \\
VC, L & $2.5 \pm 0.9$ & $2.8 \pm 0.9$ & \\
VC, \% predicted & $74.9 \pm 19.7$ & $88.9 \pm 22.5^{*}$ & \\
FVC, L & $2.5 \pm 0.9$ & $2.8 \pm 0.9$ & $9 / 19(47.4 \%)$ \\
$\mathrm{FEV}_{1}, \mathrm{~L}$ & $1.4 \pm 0.6$ & $1.9 \pm 0.6^{* *}$ & $13 / 19(68.4 \%)$ \\
$\mathrm{FEV}_{1}, \%$ predicted & $55.4 \pm 20.7$ & $72.5 \pm 18.5^{* *}$ & \\
$\mathrm{FEV}_{1} / \mathrm{FVC}, \%$ & $60.5 \pm 19.0$ & $73.3 \pm 15.3^{* *}$ & \\
$\mathrm{PEF}_{\text {, } / \mathrm{s}}$ & $3.4 \pm 1.7$ & $3.9 \pm 1.8^{* *}$ & \\
Degree of bronchial obstruction, \% & $81.4 \pm 15.3$ & $46.0 \pm 20.8^{* *}$ & \\
Pressure difference, cm $\mathrm{H}_{2} \mathrm{O}$ & $20.4 \pm 16.0$ & $3.4 \pm 4.7^{* *}$ & \\
Angle of P-P curve, degrees & $11.6 \pm 10.9$ & $33.4 \pm 11.1^{* *}$ & \\
\hline
\end{tabular}

Continuous variables before and after intervention were tested using the Wilcoxon signed-rank test. The values are represented as mean \pm standard deviation. P-P, pressure-pressure; MMRC scale, Modified Medical Research Council scale; VC, vital capacity; FVC, forced vital capacity; $\mathrm{FEV}_{1}$, forced expiratory volume in $1 \mathrm{~s}$; PEF, peak expiratory flow. MMRC responders: improvement in MMRC scale of 2 or more; FVC responders: increase in posttreatment $\mathrm{FVC}$ of $12 \%$ or greater and an absolute change of $200 \mathrm{~mL}$ or more; $\mathrm{FEV}_{1}$ responders: increase in posttreatment forced expiratory volume in $1 \mathrm{~s}$ of $12 \%$ or greater and an absolute change of $200 \mathrm{~mL}$ or more. $* p<0.05,{ }^{* *} p<0.01$.

secondary stent was implanted (Fig. 3m). After implantation, the pressure difference decreased and a small change was noted for the left side (Fig. 3k, n). After secondary stenting, the angle of the P-P curve increased from 4.9 to $28.1^{\circ}$ (Fig. 31), and the shape of P-P curve became almost linear for each bronchi (Fig. 31, o). Bronchial patency was maintained after treatment, and the MMRC scale grade decreased from 4 to 0 .

Lateral Pressure Measurement at the Bronchus

\section{Discussion}

To our knowledge, this is the first investigation to demonstrate the usefulness of P-P curves, and the measurement of $\mathrm{P}_{\text {lat }}$ at the proximal and distal sides of a bronchial obstruction during interventional bronchoscopy. The P-P curve can locate the site of maximal obstruction and assess the outcome and need for additional proce- 


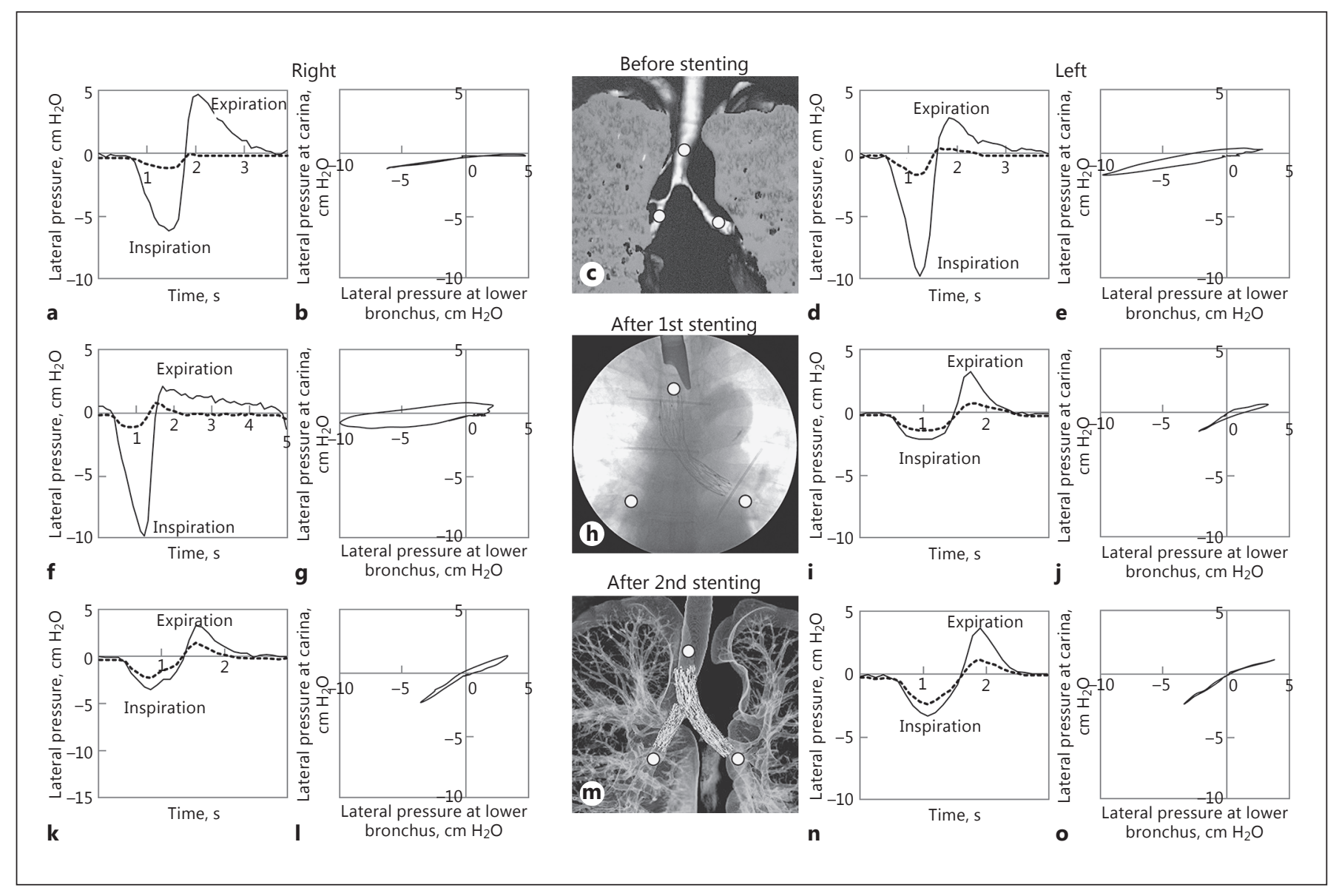

Fig. 3. a, b, $\mathbf{d}-\mathbf{g}, \mathbf{i}-\mathbf{I}, \mathbf{n}, \mathbf{o}$ Patterns of lateral airway pressure $\left(\mathrm{P}_{\text {lat }}\right)$ measurement before and after stenting for fixed bronchial obstruction due to adenocarcinoma. $\mathrm{P}_{\text {lat }}$ was measured simultaneously at the white points (carina and lower bronchus) (c, h, $\mathbf{m})$. The black lines show the lower bronchus while the dotted lines indicate the carina.

dures during interventional bronchoscopy in real time. In this study, the shape of the P-P curve was useful in providing physiological information to guide treatment decisions. It is important to predict the relief from dyspnea after interventional bronchoscopy. P-P curves displaying a straight line with a slope of $45^{\circ}$ indicate significant improvements in flow limitation and an increase in the CSA, resulting in the greatest functional benefit to patients with bronchial obstruction.

CT images can offer an advantage by viewing the airway beyond the site of bronchial obstruction when the bronchoscope cannot pass through the lesion. However, CT cannot physiologically estimate the outcome during interventional bronchoscopy. Furthermore, although bronchoscopic images can reveal the severity of bronchial obstructions, the airway mechanics are not always affected. Therefore, we added the $\mathrm{P}_{\text {lat }}$ measurement as an adjunct to bronchoscopy. After treatment, $\mathrm{P}_{\text {lat }}$ measurement was clinically useful to estimate outcomes, not only visually, but also physiologically.

We found that measuring $\mathrm{P}_{\text {lat }}$ enables instant evaluation of the respiratory function during interventional bronchoscopy.

In patients with bronchial obstruction, a hysteresis for the P-P curve can develop at the more obstructed side. Ventilation distribution to the lungs may become heterogeneous due to the complex and irregular geometry and structure of the bronchial tree and the lung parenchyma. However, the geometry of the trachea does not affect the flow distribution to the main stem bronchi $[11,12]$. Therefore, if there is no obstruction present, $\mathrm{P}_{\text {lat }}$ is uniform for the right and left main stem bronchus, and the shape of the P-P curve is linear. When an increase in phase shift between the trachea and the main stem bron- 
chi is caused by bilateral main stem bronchial obstruction, the P-P curve for the more obstructed side is seen as loop shaped. While the angle of the P-P curve is a common index for the CSA, the shape of the P-P curve is interpreted differently between tracheal and bronchial obstructions [6].

Patients with severe bronchial obstruction complain of dyspnea caused by impaired gas exchange. The obstructed side has an increase in airway resistance which delays alveolar filling compared to the unaffected side. There is a difference in the motion of the chest wall between the lungs since the rate of lung volume change is substantially less at the obstructed side. When afferent information caused by inspiratory or expiratory muscles matches the central operating phase, dyspnea is weak. However, when afferent information does not match the central phase, a sensation of discomfort might be evoked [13].

There were some limitations in our study. First, when damping of the catheter due to mucus plugging was observed, the measurement of $\mathrm{P}_{\text {lat }}$ was difficult. However, this can be easily detected as a flat line for $\mathrm{P}_{\text {lat }}$ and can be corrected by flushing the catheter with air. Second, although our method can assess airway mechanics, pulmonary perfusion status cannot be estimated. In patients with bronchial obstruction, impaired gas exchange occurs due to a ventilation-perfusion mismatch. Placement of a stent at the flow-limiting segment improves the ventilation-perfusion ratio and relieves dyspnea. In future studies, we aim to assess perfusion status by pulmonary perfusion scintigraphy and capnography to further aid in the outcome of interventional procedures.

In conclusion, P-P curves were useful in detecting the site of maximal obstruction less invasively for the optimal positioning of the stent, and for relieving dyspnea during the first intervention. Thus, our method enables patients with poorer performance status to abstain from multiple needless interventions. This is a novel technique; however, in this study the sample size was limited. Further research is required to ascertain whether the present technique adds additional value to interventional bronchoscopy.

\section{Acknowledgements}

The authors thank Mr. Jason Tonge from St. Marianna University School of Medicine for reviewing the language of this manuscript. The authors also thank Dr. Shinobu Tatsunami of the Medical Statistics Department at St. Marianna University School of Medicine for his valuable advice on the statistical analysis.

\section{Financial Disclosure and Conflicts of Interest}

This work was supported by the Japan Society for the Promotion of Science Grant-in-Aid for Scientific Research (C) (Grant No. 20590908). The funders had no role in study design, data collection and analysis, decision to publish, or preparation of the manuscript. The authors have declared that no competing interests exist.

\section{References}

1 Seijo LM, Sterman DH: Interventional pulmonology. N Engl J Med 2001;344:740-749.

2 Miyazawa T, Arita K: Airway stenting in Japan. Respirology 1998;3:229-234.

3 Miyazawa T, Yamakido M, Ikeda S, Furukawa $\mathrm{K}$, Takiguchi Y, Tada H, Shirakusa T: Implantation of Ultraflex nitinol stents in malignant tracheobronchial stenoses. Chest 2000;118: 959-965.

4 Fukuhara N, Miyazawa T, Yamashita Y, Doi M, Kuwabara M, Kamei T, Ochiai M, Ishioka S, Yamakido M: Clinical experiences of stenting in patients with esophago-bronchial fistula: report of four cases. Intern Med 2000;39: 1088-1093.

5 Miyazawa T, Miyazu Y, Iwamoto Y, Ishida A, Kanoh K, Sumiyoshi H, Doi M, Kurimoto N: Stenting at the flow-limiting segment in tracheobronchial stenosis due to lung cancer. Am J Respir Crit Care Med 2004;169:10961102.
6 Nishine H, Hiramoto T, Kida H, Matsuoka S, Mineshita M, Kurimoto N, Miyazawa T: Assessing the site of maximal obstruction in the trachea using lateral pressure measurement during bronchoscopy. Am J Respir Crit Care Med 2012;185:24-33.

7 Becker HD, Slawik M, Miyazawa T, Gat M: Vibration response imaging as a new tool for interventional-bronchoscopy outcome assessment: a prospective pilot study. Respiration 2009;77:179-194.

8 Nishine H, Hiramoto T, Kida H, Inoue T, Miyazawa T: Assessment of tracheobronchial stenosis using pressure-pressure curves by airway catheter (abstract). Eur Respir J 2009;32:752S.

9 Matsuoka S, Kurihara Y, Yagihashi K, Hoshino M, Nakajima Y: Airway dimensions at inspiratory and expiratory multisection CT in chronic obstructive pulmonary disease: correlation with airflow limitation. Radiology 2008;248:1042-1049.
10 Matsuoka S, Kurihara Y, Yagihashi K, Hoshino M, Watanabe N, Nakajima Y: Quantitative assessment of air trapping in chronic obstructive pulmonary disease using inspiratory and expiratory volumetric MDCT. Am J Roentgenol 2008; 190:762-769.

11 Elad D, Shochat A, Shiner RJ: Computational model of oscillatory airflow in a bronchial bifurcation. Respir Physiol 1998;112:95-111.

12 Otis AB, Mckerrow CB, Bartlett RA, Mead J, Mcilroy MB, Selverstone NJ, Radford EP Jr: Mechanical factors in distribution of pulmonary ventilation. J Appl Physiol 1956;8:427443.

13 Homma I, Obata T, Sibuya M, Uchida M Gate mechanism in breathlessness caused by chest wall vibration in humans. J Appl Physiol 1984;56:8-11.
Lateral Pressure Measurement at the Bronchus 